\title{
Sudanese Humanitarian Migrants in Australian Refereed Journals
}

\author{
Naduni Wickramaarachchi \\ Department of Social Inquiry, La Trobe University \\ naduniwick@gmail.com \\ Edgar Burns \\ Department of Social Inquiry, La Trobe University \\ e.burns@/atrobe.edu.au
}

\begin{abstract}
This article reviews the literature about Australian South Sudanese humanitarian migrants in refereed journals, and is underpinned by a concern for the settlement experiences of migrants and the reduced effectiveness of research which is compartmentalised into different academic disciplinary fields. Though a large volume of academic work has paid attention to many themes and issues, the present review identifies gaps in the understanding of Sudanese and South Sudanese views on family violence, economic stress, issues specific to older migrants, and perceptions of racialised policing. This article suggests the importance of bringing available knowledge from different disciplines into an accessible and crossreferenced platform to better serve southern Sudanese migrants' needs in assisting successful establishment of their new lives in Australia.
\end{abstract}

\section{Introduction}

As a migrant host country, Australia has received large numbers of migrants from all over the world since the post-world-war-two war period (Ongley and Pearson 1995). Among humanitarian migrants, southern Sudanese migrants ${ }^{1}$ showed a rapid numerical increase in Australia, 1996-

\footnotetext{
${ }^{1}$ Most Humanitarian Migrants to Australia from Sudan are from the southern region of Sudan, which is now called South Sudan. The terminology for migrants from Southern Sudan varies in the literature depending on the date of publication and generalised accounts. South Sudanese becomes a more notable demarcation after South Sudan
} 
2011 (Run, 2013, p. 20). Surveying the academic literature about southern Sudanese migrants in Australia shows a subsequent increase in research journal articles during 2010-2015 (Neumann, 2016). However, this literature is spread across different disciplines, making it harder for policy makers and researchers to access and thus limiting their capacity to see the overall situation (Albert and Hopkins, 2003).

This present article therefore attempts to organise the main themes identified in these different disciplinary journal research articles about southern Sudanese migrants in Australia. The first section provides background information about southern Sudanese humanitarian migrants. It also discusses the difficulties in distinguishing southern Sudanese migrants from broader definitions of African migrants in both Australian government reports and academic literature. The second part of the article proposes several themes emerging across the review of multiple disciplinary bodies of research. Identifying these themes shows where research has been concentrated, and also helps show where gaps are and new focus might be made.

\section{Background to Sudan and South Sudan - Humanitarian Migrants}

The Sudan conflict has been identified as one of the longest running conflicts in African history. Before Sudan's independence in 1955, the United Kingdom and Egypt shared separate administrative arrangements over the north and south under the Anglo-Egyptian Condominium. Conflict between these two parts (South Sudan and North Sudan) had started prior to independence and continued through several stages including conflicts, peace accords, agreements and referendums. The complex roots of religious differences, tribal alliances, colonial influences and issues of access to resources and power in post-colonial Sudan, are all contributing factors which caused the prolonged civil war between South and North Sudan. As a result hundreds of thousands of people were forced to migrate as refugees, or internally displaced (Brown, Miller, \& Mitchell, 2006).

In 1972 the main parties of conflict - the Government of the Democratic republic of the Sudanese $(\mathrm{GoS})$ and the Sudan Liberation Movement (SLA) - reached a tentative peace: the Addis Ababa Agreement. However, the agreement was abandoned in 1983 as conflicts continued between North

gained its statehood from Sudan in 2011. Some reports refer to Sudanese only, but they are clearly referring to southern or South Sudanese migrants. Therefore, this article uses southern Sudanese as the generic term, and only uses South Sudanese where authors have been specific about South Sudan. 
and South (Migrant Information Centre, 2012). From 1993 attempts were made to bring the main parties of the conflict for talks, eventually succeeding in signing the Comprehensive Peace Agreement (CPA) in 2005. Under the CPA both parties agreed to several regulations: a permeant ceasefire, forming an interim national unity government and conducting a referendum within six years to determine the future of South Sudan (Brangwin, 2015). After a six-year period of transition, following a referendum with 98.83 per cent of the population voting, South Sudan became independent in 2011.

As a newly formed government, however, South Sudan faced further unrest after 2013 from leadership changes in the ruling party. Ongoing conflicts disrupted civil life causing large numbers of displacements, killings and lootings across the country. This conflict was viewed as political crises within South Sudan and not as an ethnic conflict (basically not as a conflict between Dinka and Nuer) by the South Sudanese government (Thomson, 2016). However, reports published by the Human Rights Watch on the South Sudanese crises, indicated widespread killings based on ethnicity (Human Rights Watch, n.d.). The situation worsened in the December $19^{\text {th }} 2013$ attack on the United Nations (UN) compound in South Sudan killing twenty Dinka ethnic civilians and two Indian peace keepers (BBC, 2013). Even though a peace agreement was made in January 2014, violence and conflicts continue to the present time in South Sudan (Human Rights Watch, 2016; Sudan Tribune, 2016).

In the long-running series of United Nations report on South Sudan (UNMISS, 2014) an estimated 4.9 million people were still in need of humanitarian assistance at 18 November 2014. This report also estimated a further half million people had fled and were living in neighbouring countries as refugees (p. 6, para 23). To date, ongoing peace negotiations have had limited positive impact for the people of South Sudan (Human rights Watch, 2015).

Due to the humanitarian crises in Sudan, Australia accelerated its intake of refugees, with numbers peaking between 2001 and 2006 (Department of Social Services, 2015):

Compared to 62 per cent of the total overseas-born population, 5.6 per cent of the South Sudan-born people in Australia arrived in Australia prior to 2001. Among the total South Sudan-born in Australia at the 2011 Census, 72.4 per cent arrived between 2001 and 2006 and 18.4 per cent arrived between 2007 and 2011. 
The southern Sudanese population itself is diverse, including tribal, ethnic and religious variations. This has consequences for Sudanese communities in Australia, for example affecting accurate enumeration (Lucas, Jamali, \& Edgar, 2011). Refugees taking the long journey through third country hosts, and United Nations High Commissioner for Refugees (UNHCR) camps. As they to settle in a new country they may thus have widely different experiences of their leaving/arrival journeys along different routes, and also of life in their country of birth. This adds to difficulties putting precise figures on people who identify as having Sudanese or South Sudanese backgrounds (Baak, 2011a). To address these variations the Australian Bureau of Statistics Census estimates the Sudanese population in Australia mainly by working from the 'country of birth'. However, in most Australian general and media writing, people from Sudan have either been categorised as Sudanese refugees or as Sudanese humanitarian migrants.

Definitions of communities are abundant, commonly problematic, often acknowledging the lack of objective external criteria (Delanty, 2003). In the era of global migration, complexities identifying ethnic boundaries are greater than ever before. As a host country for migrants from all over the world, Australia has faced many difficulties categorising different ethnic groups (Lucas, Jamali, \& Edgar, 2011; Robinson, 2011). The complexity of defining ethnic groups is reflected in government reports as well as scholarly work. Sudanese humanitarian migrants in Australia have variously been labelled as Africans, East Africans, migrants from the Horn of Africa and as South Sudanese after independence from Sudan in 2011 (Harte, Childs, \& Hastings, 2009; Pereira, Larder, \& Somerset, 2010; Muchoki, 2015). In most cases they are identified as having come from the southern part of Sudan, prior to its independence from Sudan. However, these different terms applied to humanitarian migrants from southern Sudan in Australia neglects their past heritages and distinctive cultures (Phillips, 2011).

In Australian scholarly literature, Sudanese migrants are sometimes framed as refugees from African regions generically (Harte, Childs, \& Hastings, 2009; Robinson, 2011; Wilkinson \& Langat, 2012). However, as these migrants represent enormous diversity, they cannot be adequately aggregated into one category. As Phillips (2011, p. 59) argues, "African Australians" sets an inappropriately wide boundary as a "catch-all term for migrants and refugees coming from a range of countries under multiple visa streams." This term neglects the heterogeneous socio-economic experiences of migrants who do come from the African continent (Robinson, 2011), but 
from a selection of over fifty countries. A number of studies of African Australians truncate these migrants' diverse national and cultural origins.

One background paper shows that nearly half of the migrants from the African continent to Australia are English-speakers from South Africatherefore white and English speaking-entering under the skilled migration scheme (Hugo, 2009). However, the term "African Australians" in the rest of the literature implies migrants who have come under the 'humanitarian visa scheme' and assumes their heredity as black Africans (Phillips, 2011). The colonial conceptualisation of this 'African' population as 'others' and as subordinate cultural groups strongly impacts the imaginary of the local audience who refer verbally and in writing to 'African Australians'. Phillips (2011, p. 57) contends the "blanket application of the label 'AfricanAustralian' to new entrants from southern Sudan in particular, as well as refugees and migrants in general, homogenises their experiences and must be unpacked.”

'Horn of Africa' is another term in this literature that incorporates migrants from different countries in the African region (Dhanji, 2009; Samuel, 2013), geographically located in the north-east of Africa and covering Djibouti, Ethiopia, Eritrea and Somalia. Traditionally Sudan was not considered a country within this region, but rather as a country in North Africa (Phillips, 2011). However, in some studies Sudanese migrants have been mixed with other 'Horn of Africa' migrants (Swann, 2007). Even though there are some similarities, cultural, tribal, socio-economic and preand-post-migration experiences can be extremely different for these migrants, and research should reflect their uniqueness as much as possible. It is noteworthy that today South Sudan has self-identified with East Africa, while Sudan remains a part of North Africa.

\section{Methodology}

Since the purpose of this review was to gather refereed research articles related to the South Sudanese community in Australia, academic databases were used to identify relevant items. JSTOR and ProQuest social science databases provided journal articles and other resources in social sciences academic literature. Examining Trove, the National Library of Australia historical archival database (trove.nla.gov.au/) extended the research range. In addition a systematic search was carried out of the Australasian Review of African Studies journal as the researchers found a number of relevant articles from this specific journal not returned in the database searches. The most recent update of Neumann's (2016) Australian migrant settlement bibliography provided further items. Identified items from these sources 
were then used to look for other articles. The resulting refereed journal article collection was the basis for subsequent screening steps. Southern Sudanese migrant or refugee experiences in receiving or transition countries beyond Australia fell outside the scope of the study.

As this study covers several broad areas of inquiry, the following search strings were used to find relevant articles: all (Sudan*) and all (Australia*) and all (Sudanese*). In using the wider term 'Sudanese,' it is recognised most refugees from Sudan to Australia in recent years have been from South Sudan. While acknowledging group/community differences noted earlier, the database search term 'Sudanese' enabled maximal retrieval of potentially relevant studies.

No limits were imposed regarding publishing date or research discipline. After screening titles and abstracts, full text versions of potentially eligible papers were retrieved and reviewed. At the first stage, one hundred and thirty-six articles were identified from all sources; twenty-nine duplicate articles were excluded during screening. Further exclusions from the sample were made as follows: reports published by governments and other organisations; articles not published in refereed journals; studies that included participants from multiple African countries mixed with Sudanese migrants with substantial mixed-relevance content diluting southern Sudanese focus in the discussion (Harte, Child, \& Hastings, 2011).

Only refereed journal articles in English were selected for review. This large volume of material meets the quality criteria of refereed status and being mostly empirical studies. This review of the literature was part the first author's doctoral research project. With additional time and resources it could be extended to other sources such as theses and books or additional research outputs in non-refereed publications, and beyond the Australian political context. Although outside the present scope, this would have further added to the overall assessment of research foci to date.

\section{Research themes for South Sudanese Migrants in Australia}

The current review organised refereed journal articles according to themes. Inevitably, this could only be partially realised as each study showed unique as well as overlapping foci. While some patterns in the research work are shown, clearly other reviews might highlight different thematic combinations depending on research and disciplinary interests.

Psycho-Social Perspectives on Migrants’ Experiences

Academic interest in understanding the psychosocial wellbeing of South Sudanese migrants is significant in the Australian context. A number of 
studies have attempted to capture South Sudanese migrants' experiences in pre-migration, refugee status and post-migration from different disciplinary viewpoints (Schweitzer et al, 2006; Murray, 2010; Savage \& HickeyMoody, 2012; Marlowe, 2011a; Marlowe, 2011b; Shakespeare-Finch \& Wickham, 2009). These studies have identified positive and negative experiences in each of these stages and also revealed the positive hope South Sudanese migrants nevertheless have of fitting into Australian society.

South Sudanese migrants' psychological stress is identified in homesickness, separation from families, racial discrimination, lack of understanding of the Australian legal system, inability to access basic necessities, cultural conflicts and uncertainty of jobs (Shakespeare-Finch \& Wickham, 2009; Murray, 2010; Khawaja et al., 2008). Separation from families, having experienced violence, having witnessed the murder of a family member or friend, and lacking facilities to fulfil their basic needs were mentioned as pre-migration traumatic conditions affecting anxiety, depression, somatisation and post-traumatic stress disorder (Marlowe, 2010a; Marlowe \& Adamson, 2011). In the post-migration phase these migrants feel the loss of their family and lack of social support and social isolation (Schweitzer et al., 2006).

Coping strategies using religious beliefs and upgrading social capital have been identified by these studies (Marlowe, 2011b; Murray, 2010; Khawaja et al., 2008; Schweitzer, Greenslade, \& Kagee, 2007). Apart from these efforts, cognitive strategies such as reframing the situation, relying on available resources also help migrants to cope with their difficult situations (Khawaja et al., 2008). Schweitzer et al. (2007) described how personal attitudes and beliefs, and comparison with others less fortunate, help South Sudanese migrants cope with pre- and post-migration problems in the Australian context.

Copping, Shakespeare-Finch, and Paton (2010) examined these issues linking personal and family trauma to culturally appropriate mental care provision in a study of fifteen adult participants, drawing attention to spirituality as a key shaper of South Sudanese coping. Tempany (2009) pointed out the need for further research, drawing special attention to how South Sudanese refugees manage to cope so well despite their experiences, and the clinical implications of imposing a bio-medical model on this population.

Marlowe (2009a, 2010a, 2010b) showed the importance of listening to ordinary stories of lived experience of South Sudanese humanitarian migrants rather than applying interpretations using broad western 
discourses on trauma when working with refugees - always problematic in psychiatric or psychology focused research. Further, Marlowe (2011a) emphasized the importance of valorising research-informed teaching against anecdotal and popular perceptions of 'trauma-as-disaster' treated as fact in the social work arena. These are important attempts to engage with, and de-pathologise the terrible experiences undergone; also Marlowe, Harris and Lyons, 2013).

Even while placing refereed articles under particular themes, we acknowledge the linkages between different themes. This psycho-social literature emphasises traumatic elements in the migratory process. Studies under the next theme of adaptation and acculturation also discuss problems related to the theme of psychological stress, as well as emphasising the struggle for wellbeing.

\section{Conflicted Adaptation and Acculturation Processes}

Migrants' adaptation process and experience is another area focused on by scholars from different disciplines. Among the South Sudanese migrant academic literature in Australia a number of articles appear on this theme. A study from South East Queensland (Hebbani, Obijiofor, \& Bristed, 2010) examined acculturation issues faced by South Sudanese migrants. It identified differences in women's and men's experiences acculturating. While learning English and the fear of losing their cultural values were emphasised by women, acquiring language proficiency, questions at political, legal and social levels, perceived discrimination and their position as the head of the family were identified as issues faced by South Sudanese men. This study argued women were more closely aligned with the separation stage of the acculturation process; South Sudanese men were actively moving towards the integration stage.

Another study with twenty South Sudanese adolescents in Brisbane identified concerns over English language proficiency, issues of parental control and conflicting cultural roles as main sources for acculturation stress. This research highlighted the importance of providing culturally specific counselling services and special English language and cultural support for South Sudanese refugee children in mainstream schools (Poppitt \& Frey, 2007). Engall (2011) has also highlighted the need for providing culturally appropriate services for South Sudanese community members and emphasises the need for upgrading cultural literacy among professionals and social workers in the resettlement field. Using literature on refugees, Milner and Khawaja (2010) and Khawaja and Milner (2012) pointed out potential risks associated with the acculturation process for 
South Sudanese migrants in Australia. Their study found that in attempting acculturation, migrants may face conflicts or pressures in intergenerational relationships, gender roles, and marital relationships according to the stage that each migrant is at in this process (Whitebeach, 2014).

Hebbani, Obijiofor and Bristed (2010) described how South Sudanese women in Australia negotiate conflicts between parenting practices and marital relationships as a consequence of cross-cultural adaptation. In addition, low English language competency was highlighted as limiting these women in achieving employment and successful settlement. Hebbani et al. examined intergenerational differences faced by South Sudanese women. Most participants expressed concerns about disciplining and raising children in Australia.

Marlowe's (2011b) study of South Sudanese men's experience described the continuous struggle these migrants face adapting to a new culture while maintaining their past histories. Marlowe showed choices between two cultural values and norms were not always voluntary. The adjustment of social and institutional forces puts strong pressure on these migrants to adopt Australian values and norms, 'walking the line' between western values and their previous family and community headship (Samuel, 2013; Levi, 2014). Confrontations between gender roles and parenting practices were highlighted by participants as one of the major difficulties these migrants face where they have no control from their side of new expectations. The author argues that there is no static form of adapting but there is a fluid and continuous process negotiating between migrants' past and present.

Losoncz (2011) also investigated South Sudanese perspectives regarding their experience and identity in Australia. Interviews with nine South Sudanese Australians revealed strong feelings of disrespect towards them from the broader community in different parts of their lives (Mitchell, Kaplan, \& Crowe, 2007). Exercising coercive institutional authority over migrants, along with dismissal or ignorance of their cultural values, were keys to this sense of disrespectful treatment. Losoncz' (2015) work continues the inquiry into child abuse issues and the frustrations of 'overattention' from government agencies such as child protection authorities. Hatoss, O'Neill and Eacersall (2012) interviewed fourteen people and found that while they had a strong ethnic self-concept as South Sudanese, they also had a strong desire to create and manage an Australian identity. These writers explored the dilemma of positioning South Sudanese migrants as outsiders by mainstream society creating a high wall against them developing a full Australian identity. Hatoss (2012) developed this 
further under the everyday interactional rubric, 'where are you from,' showing the formation of South Sudanese Australian identity as somehow 'outside' and 'other.'

By focusing on the integration process of South Sudanese former refugees in Australia, Wille (2011) showed the importance of developing a sense of belonging. Her study concluded that the development of such a sense of belonging should be understood by recognising people's agency in the integration process. It also showed the importance of gender roles in the integration process. In some respects belonging-along with all its complexities - seems a richer concept than identity, incorporating many of the insights but also offering a fresher, relational, framing for the migration experience.

A number of studies have explored language maintenance and changes in South Sudanese communities in Australia (Hatoss \& Sheely, 2009; Cole, 2013; Cranitch, 2010; Hebbani et al., 2009, 2010). The findings of Hatoss and Sheely's study with sixty-four South Sudanese background secondaryschool children in Toowoomba revealed multiple uses of language in these students' daily life in this New South Wales town. The study explored how this young group are strongly attached to their mother tongue, as well as being highly motivated to learn English. Similarly, Cranitch (2010) reported on a Literacy Transition Pilot Program with South Sudanese secondary school children in Sydney, showing how creating a supportive environment for wellbeing and addressing gaps in cognitive skills, concepts of literacy and understanding about the world was necessary to achieve the targeted outcome of language programs at schools.

These studies provide a rich overview of the complex process of adjustment to a new and very different society for South Sudanese humanitarian migrants. Each piece of research picks up some element of South Sudanese experience and cultural adaptation, exploring how change has occurred and often how forms of host country resistance, such as racialised responses, from Australian society, makes the complex process tougher.

Repositioned Parenting, Families and Physical Wellbeing

Among many other pressures in the settlement period, raising children can be testing when childcare practices are different from South Sudanese migrants' previous cultural practices (Ebbeck \& Cerna, 2006). It can be argued that child-rearing practices are culturally and ecologically organised and passed through generations. Only a limited number of studies however, 
have attempted to explore child-rearing challenges for South Sudanese migrants in the Australian context (Ebbeck \& Cerna, 2006; Levi, 2014).

Using a qualitative approach Levi (2014) explored South Sudanese mothers' experiences raising adolescent children in Australia. The study showed tensions between culture and the sense of self as family, versus the western sense of 'I' played out in parenting practices. This study revealed South Sudanese mothers' fears of losing their children, both literally and symbolically. Among adaptation methods, using more conversations with children rather than physical forms of discipline, using social networks to learn new child-rearing practices, and using a combination of cultural practices, were all identified as new adjustments made by these South Sudanese mothers. Ebbeck and Cerna (2007) similarly argued that one has to compromise some practices to accommodate the demands of the current environment.

Different gendered and cross-national perspectives again appear in Grabska's (2010) fifteen month-long ethnographic study of cross-national marriage 'offers'. This article analysed 'lost boys' who moved to rich countries and who later returned to offer marriage for 'invisible girls' in camps. It showed how this may (out)compete local boys who stayed behind in camps. These transnational activities of refugees settled in western countries create gender asymmetries among those who stayed behind in camps (Grabska, 2010, p. 479). Such transnational marriages reproduce social and cultural relations, maintaining identity and belonging and practicing kinship and family ties.

In the health sector only a limited number of studies have attempted to explicate the physical health challenges South Sudanese migrants face in Australia. Renzaho, Bilal, and Marks (2014) pointed out the lack of studies examining post-migration health needs and issues of South Sudanese refugees in Australia. Using a quantitative approach, they attempted to assess the prevalence of obesity and obesity-related conditions of South Sudanese migrants in Brisbane. Despite being described as refugees who had faced food insecurity, hunger and under-nutrition during the journey, the study sample showed high levels of obesity and high blood pressure compared to the host country populace. The study emphasised the need for more research on health-related issues for migrants in terms of mental and physical wellbeing pressures adjusting to a new environment.

Yeoh and Furler's (2011) qualitative study with Sudanese participants in West Melbourne, explored how members of the Dinka South Sudanese community perceive diabetes within the context of their broader health circumstances. The study showed dislocation from familiar environment 
and different life experiences throughout their journey have significant impacts on their perceptions on health. Another study in South Australia (Mude, Burgess, \& Mwanri, 2013) focused on understanding South Sudanese parents' perceptions of childhood obesity and being overweight. The study identified issues such as food access, the quality of available food, the role of parents, physical inactivity and some features of local environment have as health issues for South Sudanese communities.

Sneesby et al. (2011) attempted to understand cultural differences interpreting stages of life for different cultural groups, especially South Sudanese migrants in Australia. This study raised communication issues related to cultural discourse and consent, concepts of disease and illness, attitudes towards treatments, customs related to death, dying and bereavement and spiritual and religious beliefs. These were discussed as healthcare sector barriers to constructively working with South Sudanese community groups. Similarly, Tankink (2013) explored the complexities for South Sudanese women in speaking out about sexual violence; and Rogers and Earnest (2015) reported reproductive health communication issues for Sudanese and Eritrean women in their Brisbane study.

In contrast, Muchoki (2015) applies the concept of 'intimate citizenship' to articulate difficulties South Sudanese and other men face in their migrant transition: from male dominant positioning relative to family, partner and as political position, to formal gender equality as Australian citizens with public rules constraining conduct of primary relationships. On the other side of gender specific research, Rogers and Earnest (2015) conducted focus group discussions for older and younger women to consider aspects of their sexual and reproductive health. They elicited participants' suggestions for better communication within their family environments. This positive engagement also identified issues of cultural insensitivity and exclusion affecting sexual and reproductive health and good quality relationships.

Family functioning as the primary mechanism of support that refugees draw upon to achieve a sense of wellbeing both physically and emotionally is a valuable area of research and each of the areas examined above contributes to better understanding of adaptation to the Australian setting. This is not a simple transfer but difficult translation of cultural values and family practices further encumbered by the social dislocation that has led them here in the first place. 
Interfacing with the Educational Sector

For southern Sudanese migrants the education system is one of the areas that has been given some attention in Australia (Brown, Miller, \& Mitchell, 2006; Turner \& Fozdar, 2010; Hatoss \& Huijser, 2010). Turner and Fozdar (2010) investigated the experience of adult learners in an urban setting while Major et al. (2013), focused on understanding how young learners overcome educational issues in a rural setting. Both studies described the importance of bonding as well as bridging social capital in achieving success educationally. Further, Major et al. (2013) pointed out opportunities in regional and rural settings to develop bridging networks especially for new migrants.

In other education research Hatoss and Huijser (2010) attempted to identify the role of education in the resettlement process of South Sudanese refugees, particularly women, in Australia. They outlined how these women from refugee backgrounds faced cultural and linguistic hurdles accessing educational opportunities. Further, this study showed how Sudanese women dealt with burdens of family responsibilities and socially constructed gender roles. However, generally both men and women showed high motivation in gaining education as an asset to adjust to their new country and also as a way of supporting their communities back in Sudan or South Sudan.

Similarly, Turner (2007) explored different ways women and men negotiated their expectations of the educational process with their teachers. Using an ethnographic approach across different learning environments, this study showed different levels of congruence between teachers', volunteers' and students' expectations of how classes would be conducted. The study explained how, in contrast to university-level education, community-level learners showed more positive attitudes towards teachercentred and pastoral teaching approaches.

Turner's (2013) study with South Sudanese students pointed out how reflective practice facilitated pre-service teachers' skills in teaching in culturally diverse classrooms. Turner and Fozdar (2010) also discussed language and other pedagogical needs in university learning-support classes. In another article Turner (2010) explored how second language students' learning needs can be met in university support classes. This indicated that students benefit from some modifications in teaching practices, since their ambivalent reactions to discussion-based teaching, in particular, proved to be an obstacle to their learning in the support classes.

Blockages and aspirations for South Sudanese students in the education system was also researched in other studies in the Australian context 
(Brown, Miller, \& Mitchell, 2006; Hatoss, O’Neill, \& Eacersall, 2012). Most of these studies emphasised high levels of career aspiration of South Sudanese students even though they face a multitude of practical and discursive impediments. The participants in these studies also showed a strong desire to use education in supporting their community in Australia and back in Sudan through educational success.

Harris (2011a) worked with young South Sudanese women in education, helping them to make their cultural and visual difference work for them. She applied hooks' (1994) idea of “transgressivity" to challenge migranthost positioning in Australia. In further work, migrant processes generally are illuminated in the multiple threads of South Sudanese experiences in Australia (Harris \& Marlowe, 2011).

Recent work by Harris, Marlowe and Nyuon (2015) explicitly challenged essentialising discourses that collapse racist/settler host paradoxes onto South Sudanese migrants to Australia as "melancholy migrants." Resisting such interpretations in educational settings is possible. They are better interpreted as "multiple ways of knowing" (p. 1236). This acknowledges South Sudanese capacities of resilience and adaptability expressed in gendered and other new "identities and practices." An example of one of these "multiple ways of knowing" is Hatoss' (2014) work on adult migrant language programs.

Alternative research concepts and advocacy of policy or practical strategies enrich the discussion and show the overflowing of themes, for example in Cole's (2013) application of Deleuze's (1994) ideas of the "virtual" and "narrative real" to South Sudanese multiple literacies (Masny, 2010). This explored South Sudanese migrant experience challenging common binaries. Cassity and Gow's (2005) study with young South Sudanese refugees showed difficulties in transferring from one country to another and emphasised schools as a space in which migrants can feel they belong as a part of their everyday life experience.

This education theme reflects active sites of change and empowerment of individuals within a key Australian institution. This literature also indicates a maturing of analytic mode in combining social theory concepts in addressing South Sudanese equity needs. It also shows scholars deploying the emancipating capacities of these concepts from the broader academic enterprise (Hanson-Easey et al., 2014).

Institutional 'Othering' in Mass Media and the Legal System

The mass media and the legal processes, in particular policing, are two major institutional spheres in which South Sudanese migrants to Australia 
are subjected to substantial 'othering'. These interactions and representations frequently adversely impact how South Sudaneseespecially but not solely youth-are repeatedly misrepresented, maligned and mistreated despite their Australian citizenship status and keenness to be involved in their new homeland (Wilson, 2011).

A number of studies within this general theme of 'othering', show southern Sudanese migrants negatively portrayed in the Australian mass media. In particular, these studies increased soon after the murder of nineteen year old South Sudanese migrant Liep Gony by two 'white' Australian men in the Melbourne suburb of Dandenong in 2007. Indeed, a media frenzy erupted creating moral panic (Baak, 2011a, 2011b; Gatt, 2011). Despite the fact that he was killed as a result of racial attack, the news reports created a discourse that attempted to highlight it as his fault (Due, 2008; Windle, 2008; Nunn, 2010).

Baak (2011b) showed how the Australian media in general creates otherness towards South Sudanese migrants by portraying them as strangers to Australia and describing how such negative attitudes affect and justify Australian political decisions towards asylum seekers. Further, her studies documented media discourses and community talk which occurred soon after the murder of Ngong Akok Akol in the Western suburbs of Adelaide, 2009, and demonstrates how this affected the sense of belonging within the South Sudanese community both within the wider Australian society and also inside their own community (Baak, 2011a, 2011b). These studies showed that when a broad sense of belonging is questioned, minority groups tend to tighten their cultural bond to create a collective identity to safeguard themselves.

Nolan et al. (2011) attempted to capture how Australian mass media represented South Sudanese migrants during the election period of 2007 and how this representation interpreted and undercut Australian multiculturalism. Through analysing Australia's three major newspapers' reports about South Sudanese migrants in the period September 2007-April 2008, this study traced media discourse around visible minorities, especially around South Sudanese migrants. Again the narrative situated them as outsiders to the multicultural Australian community and created a significant bar to practical implementation of inclusive multiculturalism.

Conflict between Sudanese and Australian cultural values and customs has been discussed or is implicit in a number of academic articles in various ways. Two studies explored the difference between South Sudanese customary law and the Australian legal system, and challenges faced by both sides in practical life (Juuk, 2013; Milos, 2011). Both studies focused 
on comparing South Sudanese customary family law with Australian family law. Juuk (2013) identified differences of Sudanese and Australian laws with a special focus on marriage, divorce and child custody. Even though Sudanese and Australian laws show similarities in their main objective: reinforcement and maintenance of a peaceful society, this article showed the majority of Dinka marriages and family practices are different and face adjustment pressures within Australian family law about physical conduct between partners and managing children. From similar research Milos (2011) pointed out the importance of providing better education for South Sudanese refugees in Australia about the Australian legal system as well as the need for acknowledging traditional customary mores and processes of South Sudanese communities within the Australian legal framework.

Dawes' (2013) Queensland study explored a different legal question: how South Sudanese youth interact with the criminal justice system in Australia. This study showed how negativity created by the media, clear visibility in public places, misunderstanding of South Sudanese culture by police and being victims of police harassment, have all hindered the possibilities of building positive interaction with the justice system in the experiences of these young people. He described strategies to develop better relations between South Sudanese young people and police: training to increase the cultural awareness of police, consultation of Sudanese elders to mediate matters between young people and police, recruiting more police officers from the South Sudanese community, and educating South Sudanese people on their rights and responsibilities in relation to the criminal justice system. Using secondary data, Run (2013) discussed how South Sudanese refugees experience racial profiling and how policing practices particularly impact the South Sudanese community in terms of social exclusion by tougher policing over minor matters. Racial profiling constitutes a major stumbling block in the settlement process and is an extra burden on refugees.

\section{Community Development and Research Approaches}

In the academic literature about the southern Sudanese community in Australia, some studies attempted to open new avenues with research methodologies that can be employed studying different ethnic groups especially South Sudanese migrants (Mitchell et al., 2007). Westoby (2008) suggested emic perspectives are an appropriate way to work with South Sudanese migrants in the community development sector. Using this perspective allows "stepping back and re-engagement with how South Sudanese refugees define their own needs and losses” (Westoby, 2008, p. 
490). An emic perspective engages the challenges that these migrants face from their own perspective. Westoby noted that such dialogue creates "a platform that takes seriously the need to rebuild a new social world" (p. 491). Similarly, Engall (2011) reflected on South Sudanese cultural practices in Australia, showing the importance of using migrants' cultural knowledge and practices within settlement processes. Marlowe (2009a, 209b, 2010b) described the importance of listening to ordinary stories of lived experience of South Sudanese humanitarian migrants rather than interpretations using broad western discourses on trauma when working with refugees.

Further, Marlowe (2011a) emphasized the importance of researchinformed teaching over against anecdotal and popular perceptions of 'trauma-as-disaster' treated as fact in the social work arena. This complemented other work by Harris and Nyuon (2010) discussing the importance of using art-based methodologies with different ethnic groups in terms of building collaborative knowledge. Marlowe (2010b) outlined employing narrative principles of double-listening and double-storied testimony as an approach, already utilised in professional practice and community engagements.

In terms of community adaptation settlement processes, Hebbani and Van Vuuren (2015) explored Queensland South Sudanese experiences of active community radio broadcasting and their shifting preferences towards digital and online media forms, seen for instance in a South Sudanese blogger co-operative (PaanLuel Wël, 2016). Attempting to find new ways to improve facilities for young South Sudanese women in the educational sector, Harris (2011b) pointed out the importance of innovating new research approaches such as an ethno-cinematic method. She argued such approaches allow opportunities for connecting and exchanging knowledge and sharing power. From her ethnocinematic research project, CrossMarked: Sudanese Young Women Talk Education, with young South Sudanese women she "explore[d] the potential of alternative pedagogies, which include popular culture, especially audio-visual forms, to engage teachers and learners with one another in collaborative pedagogical methods" (p. 729). Harris opened a new vison towards young South Sudanese women. She proposed that, "this richness of encounter cannot easily be interpreted and presented as research without a multimodal approach" (2011b, p. 740).

This multiple-threaded approach can be seen in other studies such as Dean et al. (2013) discussing issues involved in doing sexuality research with South Sudanese youth, or Baak (2015) describing the sense of 
obligation and sustaining family links for southern Sudanese Dinka women sending remittances from Australia.

\section{Conclusion}

This article has looked across the refereed journal literature of South Sudanese migrants' experiences in Australia. The collection of articles from various academic disciplines was analysed in terms of six intertwined themes -

1. Psycho-Social Perspectives on Migrants’ Experiences

2. Conflicted Adaptation and Acculturation Processes

3. Repositioned Parenting, Families and Physical Wellbeing

4. Interfacing with the Educational Sector

5. Institutional 'Othering' in Mass Media and the Legal System

6. Community Development and Research Approaches

Some of these themes were more the expression of one discipline rather than another, for instance, psychological and psychosocial wellbeing, or legal processes.

While in the large scheme of Southern Sudanese transition processes these studies individually provide knowledge in a number of different areas. However, there are gaps in the research understanding South Sudanese experiences in terms of their economic activities, both success and lack of success, and issues around elderly migrants. How these migrants can and do actively build their sense of belonging deserves continuing attention as positive engagement (Levitt \& Jaworsky, 2007).

Neumann's (2016, p. 3) general bibliography about migrant settlement in Australia notes "much of the scholarship published in the past ten years is exclusively concerned with the settlement of Southern Sudanese refugees. More than seventeen per cent of all texts published or successfully submitted since 2010 are about southern Sudanese refugee migrants”. Neumann identifies five broad gaps in the Australian migrant settlement literature: lack of comprehensiveness, insufficient engagement with government policy, limited historical framing, barriers to settlement, and treatment of return migration. The fourth gap can be seen in the Sudanese research considered here: "scholars have tended to be concerned with identifying obstacles to the successful resettlement of refugees. In doing so, they have focused on the refugees themselves” (Neumann, 2016, p. 3). While in one sense this is obvious, on the other hand it alerts researchers to the importance of Australian institutional adaption-successes and failures - as also worth pursuing and documenting. Neumann's observation has value in assessing Sudanese settlement processes and pressures. 
Further assemblage or combination of these contributions to knowledge from different disciplines is desirable to open pathways for a smoother transition for South Sudanese migrants. Ideally multiple disciplines' research becomes multidisciplinary research. This present journal's aim to serve cross-disciplinarily, helps the integrative agenda so that continuing work on psychological, legal, family practices and law enforcement themes, can reach beyond the confines of western disciplinary academic truths. As different aspects of migrants' life experiences and challenges have been considered, insights into their overall settlement and adjustment in a new country have been achieved. It continues to be of high importance to bring all available knowledge in different disciplines into accessible and crossreferenced platform to better serve South Sudanese migrants' needs in the successful establishment of their new lives in Australia.

\section{Bibliography}

Abur, W. (2012). The settlement challenges facing south Sudanese refugee community in the Western of suburbs of Melbourne (Masters thesis). Victoria University, Melbourne, VIC.

Albert, M., \& Hopkins, A. (2003). Building bridges between academics and service providers to Sudanese refugees in Australia. Australasian Review of African Studies, 25(2), 99-102.

Baak, M. (2011a). Diasporic mourning and negotiating belonging in response to murder. Social Alternatives, 30(2), 9-12.

Baak, M. (2011b). Murder, community talk and belonging: An exploration of Sudanese community responses to murder in Australia. African Identities, 9(4), 417-434.

Baak, M. (2015). Transnational families, remittances, cieng and obligation for Dinka women in Australia. Emotion, Space and Society, 16, 123129.

BBC. (2013). Indian UN peacekeepers killed in S Sudan attack. http://www.bbc.com/news/world-africa-25456862

Brangwin, N. (2015, 17 April). South Sudan crisis (pp. 1-14), Research Paper Series 2014-15. Canberra, ACT: Parliament Library of Australia.

Brown, J., Miller, J., \& Mitchell, J. (2006). Interrupted schooling and the acquisition of literacy: Experiences of Sudanese refugees in Victorian secondary schools. Australian Journal of Language and Literacy, 29(2), 150-162. 
Cassity, E., \& Gow, G. (2005). Making up for lost time: The experience of Southern Sudanese young refugees in high schools. Youth Studies Australia, 24(3), 51-55.

Cole, D. (2013). Deleuze and narrative investigation: The multiple literacies of Sudanese families in Australia. Literacy, 47(1), 35-41.

Copping, A., Shakespeare-Finch, J., \& Paton, D. (2010). Towards a culturally appropriate mental health system: Sudanese-Australians' experiences with trauma. Journal of Pacific Rim Psychology, 4(1), 53-60.

Cranitch, M. (2010). Developing language and literacy skills to support refugee students in the transition from primary to secondary school. Australian Journal of Language and Literacy, 33(3), 255-267.

Dawes, G. (2013). Sudanese 'Lost boys' and their interactions with the criminal justice system in Queensland Australia. International Journal of Social Inquiry, 6(1), 73-89.

Dean, J., Wollin, J., Stewart, D., Debattista, J., \& Mitchell, M. (2012). Hidden yet visible: methodological challenges researching sexual health in Sudanese refugee communities. Culture, Health and Sexuality, 14(8), 911-924.

Delanty, G. (2003). Community. London: Routledge.

Deleuze, G. (1994). Difference and repetition. London: Athlone.

Department of Social Services. (2015) Community Information Summary: South Sudan-born, Historical Background. Department of Immigration and Citizenship, Canberra, ACT.

Dhanji, S. (2009). Welcome or unwelcome? Integration issues and the resettlement of former refugees from the Horn of Africa and Sudan in metropolitan Melbourne. Australasian Review of African Studies, 30(2), 152-178.

Due, C. (2008). 'Who are strangers?': ‘Absorbing' Sudanese refugees into a white Australia. Australian Critical Whiteness Studies Association Journal, 4(1), 1-13.

Ebbeck, M., \& Cerna, C. (2006). A study of child rearing practices amongst selected Sudanese families in South Australia: Implications for child care services. Early Childhood Education Journal, 34(5), 307-314.

Engall, P. (2011). No room in my car. Australasian Review of African Studies, 32(2), 194-203.

Gatt, K. (2011). Sudanese refugees in Victoria: An analysis of their treatment by the Australian Government. International Journal of Comparative and Applied Criminal Justice, 35(3), 207-219. 
Grabska, K. (2010). Lost boys, invisible girls: Stories of Sudanese marriages across borders. Gender, Place and Culture, 17(4), 479497.

Hanson-Easey, S., Augoustinos, M., \& Moloney, G. (2014). 'They're all tribals': Essentialism, context and the discursive representation of Sudanese refugees. Discourse and Society, 25(3), 362-382.

Harris, A. (2011a). Neir Riel (Strong girls): Transgression and fugitive spaces in Sudanese Australian classrooms. Qualitative Inquiry, 17(8), 750-759.

Harris, A. (2011b). Singing into language: Sudanese Australian young women create public pedagogy. Discourse: Studies in the Cultural Politics of Education, 32(5), 729-743.

Harris, A., \& Marlowe, J. (2011). Hard yards and high hopes: The educational challenges of African refugee students in Australia. International Journal of Teaching and Learning in Higher Education, 23(2), 186-196.

Harris, A., \& Nyuon, N. (2010). Working it both ways: Intercultural collaboration and the performativity of identity. Australasian Review of African Studies, 31(1), 62-81.

Harris, A., Marlowe, J., \& Nyuon, N. (2015). Rejecting Ahmed's 'melancholy migrant': South Sudanese Australians in higher education. Studies in Higher Education, 40(7), 1226-1238.

Harte, W., Childs, I., \& Hastings, P. (2009). Settlement patterns of African refugee communities in Southeast Queensland. Australian Geographer, 40(1), 51-67.

Hatoss, A. (2012). Where are you from? Identity construction and experiences of 'othering' in the narratives of Sudanese refugeebackground Australians. Discourse and Society, 23(1), 47-68.

Hatoss, A. (2013). Displacement, language maintenance and identity: Sudanese refugees in Australia. Amsterdam/Philadelphia, PA: John Benjamins.

Hatoss, A. (2014). Caught between policies and practices: Sudanese migrants' experiences of AMEP in Australia. International Journal of Pedagogies and Learning, 9(3), 193-210.

Hatoss, A., \& Sheely, T. (2009). Language maintenance and identity among Sudanese-Australian refugee-background youth. Journal of Multilingual and Multicultural Development, 30(2), 127-144.

Hatoss, A., \& Huijser, H. (2010). Gendered barriers to educational opportunities: Resettlement of Sudanese refugees in Australia. Gender and Education, 22(2), 147-160. 
Hatoss, A., O’Neill, S., \& Eacersall, D. (2012). Career choices: Linguistic and educational socialization of Sudanese-background high-school students in Australia. Linguistics and Education, 23(1), 16-30.

Hebbani, A., Obijiofor, L., \& Bristed, H. (2009). Generational differences faced by Sudanese refugee women settling in Australia. Intercultural Communication Studies, 17(1), 66-82.

Hebbani, A., Obijiofor, L., \& Bristed, H. (2010). Intercultural communication challenges confronting female Sudanese former refugees in Australia. Australasian Review of African Studies, 31(1), 37-61.

Hebbani, A., \& Van Vuuren, K. (2015). Exploring media platforms to serve the needs of the South Sudanese former refugee community in Southeast Queensland. Journal of Immigrant and Refugee Studies, 13(1), 40-57.

hooks, b. (1994). Teaching to transgress: Education as the practice of freedom. New York, NY: Freedom.

Hugo, G. (2009). Migration between Africa and Australia: A demographic perspective (pp. 1-70). Sydney, NSW: Australian Human Rights Commission.

Human Rights Watch. (n.d.). Countries: South Sudan. https://www.hrw.org/africa/south-sudan

Human rights Watch. (2015). World Report 2015: Sudan: Events of 2014. https://www.hrw.org/world-report/2015/country-chapters/ sudan

Human Rights Watch. (2016). South Sudan: Civilians killed, tortured in Western Region. https://www.hrw.org/news/2016/05/24/southsudan-civilians-killed-tortured-western-region

Juuk, B. (2013). South Sudanese Dinka customary law in comparison with Australian family law: Legal implications for Dinka families. Australasian Review of African Studies, 34(2), 99-112.

Khawaja, N., White, K., Schweitzer, R., \& Greenslade, J. (2008). Difficulties and coping strategies of Sudanese refugees: A qualitative approach. Transcultural Psychiatry, 45(3), 489-512.

Khawaja, N., \& Milner, K. (2012). Acculturation stress in South Sudanese refugees: Impact on marital realtionships. International Journal of Intercultural Relationships, 36(5), 624-636.

Levi, M. (2014). Mothering in transition: The experiences of Sudanese refugee women raising teenagers in Australia. Transcultural Psychiatry, 51(4), 479-498. 
Levitt, P., \& Jaworsky, B. (2007). Transnational migration studies: Past developments and future trends. Annual Review of Sociology, 33, 129-156.

Losoncz, I. (2011). Blocked opportunity and threatened identity: Understanding experiences of disrespect in South Sudanese Australians. Australasian Review of African Studies, 32(2), 118-142.

Losoncz, I. (2015). 'The government just stops parents parenting'—Finding better ways to build safety around children in families from a refugee background. Child Abuse and Neglect. RegNet research paper 76.

Lucas, D., Jamali, M., \& Edgar, B. (2011). The Sudan-born in Australia: A statistical profile. Australasian Review of African Studies, 32(2), 1024.

Major, J., Wilkinson, J., Langat, K., \& Santoro, N. (2013). Sudanese young people of refugee background in rural and regional Australia: Social capital and education success. Australian and International Journal of Rural Education, 23(3), 95-105.

Marlowe, J. (2009a). Accessing 'authentic knowledge': Being and doing with the Sudanese community. The Australian Community Psychologist, 21(1) 39-49.

Marlowe, J. (2009b). Conceptualising refugee resettlement in contested landscapes. Australasian Review of African Studies, 30(2), 128-151.

Marlowe, J. (2010a). Beyond the discourse of trauma: Shifting the focus on Sudanese refugees. Journal of Refugee Studies, 23(2), 183-198.

Marlowe, J. (2010b). Using a narrative approach of double-listening in research contexts. International Journal of Narrative Therapy and Community Work, 41(3), 41-51.

Marlowe, J. (2011a). Sudanese settlement: Employing strategies of intercultural contact and cultural maintenance. Australian Review of African Studies, 32(2), 101-117.

Marlowe, J. (2011b). 'Walking the line': Southern Sudanese masculinities and reconciling one's past with the present. Ethnicities, 12(1), 1-17.

Marlowe, J., \& Adamson, C. (2011). Teaching trauma: Critically engaging a troublesome term. Social Work Education: The International Journal, 30(6), 623-634.

Marlowe, J., Harris, A., \& Lyons, C. (Eds.). (2013). South Sudanese diaspora in Australia and New Zealand: Reconciling the past with the present. Newcastle-Upon-Tyne, UK: Cambridge Scholars.

Masny, D. (2010). Multiple literacies theory: How it functions, what it produces. Perspectiva, 28(2), 337-352 
Migrant Information Centre. (2012, May). South Sudanese cultural profile (pp. 1-9). Melbourne, VIC: Migrant Information Centre.

Milner, K., \& Khawaja, N. (2010). Sudanese refugees in Australia: The impact of acculturation stress. Journal of Pacific Rim Psychology, 4(1), 19-29.

Milos, D. (2011). South Sudanese Communities and Australian family law: A clash of systems. Australasian Review of African Studies, 32(2), 143-159.

Mitchell, J., Kaplan, I., \& Crowe, L. (2007). Two cultures: One life. Community Development Journal, 42(3), 282-298.

Muchoki, S. (2015). Using 'intimate citizenship' to make sense of the experiences of men with refugee backgrounds in Australia. Culture, Health and Sexuality, 17(sup. 1), 61-73.

Mude, W., Burgess, T., \& Mwanri, L. (2013). 'We should eat it wisely, in a good way': Knowledge, perceptions and understanding of childhood obesity and overweight among Sudanese refugee parents in South Australia. Australasian Review of African Studies, 34(2), 113-133.

Murray, K. (2010). Sudanese perspectives on resettlement in Australia. Journal of Pacific Rim Psychology, 4(1), 30-43.

Neumann, K. (2016). The resettlement of refugees in Australia: A bibliography (7th ed.). Melbourne, VIC: Institute of Social Research, Swinburne University.

Nolan, D., Farquharson, K., Politoff, V., \& Marjoribanks, T. (2011). Mediated multiculturalism: Newspaper representations of Sudanese migrants in Australia. Journal of Intercultural Studies, 32(6), 655675.

Nunn, C. (2010). Spaces to speak: Challenging representations of Sudanese-Australians. Journal of Intercultural Studies, 31(2), 183198.

Ongley, P., \& Pearson, D. (1995). Post-1945 International migration: New Zealand, Australia and Canada compared. The International Migration Review, 29(3), 765-793.

PaanLuel Wël. (2016). PanLuel Wël: South Sudanese Bloggers. https://paanluelwel.com/

Pereira, C., Larder, N., \& Somerset, S. (2010). Food acquisition habits in a group of African refugees recently settled in Australia. Health and Place, 16(5), 934-941.

Phillips, M. (2011). Convenient labels, inaccurate representations: Turning southern Sudanese Refugees into 'African-Australians'. Australasian Review of African Studies, 32(2), 57-79. 
Poppitt, G., \& Frey, R. (2007). Sudanese adolescent refugees: Acculturation and acculturative stress. Australian Journal of Guidance and Counselling, 17(2), 160-181.

Renzaho, A., Bilal, P., \& Marks, G. (2014). Obesity, type 2 diabetes and high blood pressure amongst recently arrived Sudanese refugees in Queensland, Australia. Journal of Immigrant Minority Health, 16(1), 86-94.

Robinson, J. (2011). Sudanese heritage and living in Australia: Implications of demography for individual and community resilience. Australasian Review of African Studies, 32(2), 25-56.

Rogers, C., \& Earnest, J. (2015). Sexual and reproductive health communication among Sudanese and Eritrean women: An exploratory study from Brisbane, Australia. Culture, Health and Sexuality, 17(2), 223-236.

Run, R. (2013). Unnecessary encounters: South Sudanese refugees' experiences of racial profiling in Melbourne. Social Alternatives, 32(3), 20-25.

Samuel, M. (2013). '[In Australia] what comes first are the women, then children, cats, dogs, followed by men': Exploring accounts of gender relations by men from the Horn of Africa. Australasian Review of African Studies, 34(2), 78-98.

Savage, G., \& Hickey-Moody, A. (2010). Global flows as gendered cultural pedagogies: Learning gangsta in the 'Durty South'. Critical Studies in Education, 51(3), 277-293.

Schweitzer, R., Melville, F., Steel, Z., \& Lacherez, P. (2006). Trauma, postmigration living difficulties, and social support as predictors of psychological adjustment in resettled Sudanese refugees. Australian and New Zealand Journal of Psychiatry, 40(2), 179-188.

Schweitzer, R., Greenslade, J., \& Kagee, A. (2007). Coping and resilience in refugees from the Sudan: A narrative account. Australian and New Zealand Journal of Psychiatry, 41(3), 282-288.

Shakespeare-Finch, J., \& Wickham, K. (2009). Adaptation of Sudanese refugees in an Australian context: Investigating helps and hindrances. International Migration Review, 48(1), 23-46.

Sneesby, L., Satchell, R., Good, P., \& Riet, P. (2011). Death and dying in Australia: Perceptions of a Sudanese community. Journal of Advanced Nursing, 67(12), 2696-2702.

Sudan Tribune. (July 19, 2016). African Union approves regional force for South Sudan. http://www.sudantribune.com/ 
Swan, B. (2007). Horn of Africa and Sudanese communities in Victoria. Melbourne VIC: Ethnic Communities' Council of Victoria, Policy Discussion Paper 2, 1-28.

Tankink, M. (2013). The silence of South-Sudanese women: Social risks in talking about experiences of sexual violence. Culture, Health and Sexuality, 15(4), 391-403.

Tempany, M. (2009). What research tells us about the mental health and psychosocial wellbeing of Sudanese refugees: A literature review. Transcultural Psychiatry, 46(2), 300-315.

Thomson, S. (2016). South Sudan: 'One of the most horrendous human rights situations in the world', says UN. World Economic Forum. 15 March, https://www.weforum.org/agenda/2016/03/south-sudan-oneof-the-most-horrendous-human-rights-situations-in-the-world-says$\underline{\mathrm{un} /}$

Turner, M. (2007). South Sudanese learners in Western Australia: Learning environments, expectations and participation. In V. Colic-Peisker \& F. Tilbury (Eds.), Settling in Australia: The social inclusion of refugees (pp. 23-37). Perth, WA: Murdoch University, Centre for Social and Community Research.

Turner, M. (2010). Using student co-regulation to address L2 students' language and pedagogical needs in university support classes. Language and Education, 24(3), 251-26.

Turner, M. (2013). Beyond the 'good teacher': Guiding pre-service teacher reflections on culturally diverse students. Teachers and Teaching: Theory and Practice, 19(1), 78-92.

Turner, M., \& Fozdar, F. (2010). Negotiating 'community' in educational settings: Adult South Sudanese students in Australia. Journal of Intercultural Studies, 31(4), 363-382.

UNMISS (United Nations Mission in the Republic of South Sudan). (2014). Report of the Secretary-General on South Sudan, 18 Nov 2014. http://www.un.org/en/ga/search/view_doc.asp?symbol=S/2014/821

Westoby, P. (2008). Developing a community-development approach through engaging resettling Southern Sudanese refugees within Australia. Community Development Journal, 43(4), 483-495.

Whitebeach, T. (2014). Three Madi projects in Tasmania. Oral History Association of Australia Journal, 36, 16-22.

Wilkinson, J., \& Langat, K. (2012). Exploring educators' practices for African students from refugee backgrounds in an Australian regional high school. Australasian Review of African Studies, 33(2), 158-177. 
Wille, J. (2011). Agency and belonging: Southern Sudanese refugees' reflections on life in Australia. Australasian Review of African Studies, 32(2), 80-100.

Wilson, M. J. (2011). 'Making space, pushing time': A Sudanese hip-hop group and their wardrobe-recording studio. International Journal of Cultural Studies, 5(1), 47-64.

Windle, J. (2008). The racialisation of African youth in Australia. Social Identities, 14(5), 553-566.

Yeoh, S., \& Furler, J. (2011). Perceptions of health and diabetes in a Melbourne South Sudanese community. Journal of Immigrant Minority Health, 13(5), 914-918.

Zetter, R. (1991). Labelling refugees: Forming and transforming a bureaucratic identity. Journal of Refugee Studies, 4(1), 39-62. 